Bioscientia Medicina: Journal of Biomedicine \& Translational Research

Journal Homepage: www.bioscmed.com

\title{
Epidermal Proliferation and Differentiation in Ichthyosis Vulgaris
}

\author{
Nopriyati ${ }^{1,2}$, Deddy ${ }^{1,2 *}$, Rusmawardiana ${ }^{1,2}$, Mutia Devi ${ }^{1,2}$
}

${ }^{1}$ Department of Dermatology and Venereology Faculty of Medicine Universitas Sriwijaya, Palembang, Indonesia

${ }^{2}$ Department of Dermatology and Venereology, RSUP Dr. Moh Hosein Palembang, Indonesia

\section{A R T I C L E I N F O}

Keywords:

Proliferation

Differentiation

Filaggrin

Ichthyosis vulgaris

\section{*Corresponding author: \\ Deddy \\ E-mail address: docdeddy@gmail.com}

\begin{abstract}
A B S T R A C T
Epidermal proliferation and differentiation is a physiological process which plays crucial role in protecting human body from external environment. Ichthyosis vulgaris is a disease caused by disruption of epidermal differentiation process. Disrupted of profilaggrin conversion to filaggrin caused by mutations from the filaggrin gene (FLG) located on chromosome 1q21. Recently, caused of ichthyosis vulgaris is mutation of the CASP14 gene on chromosome 19p13.12 which produces caspase-14, is involved in the proteolytic degradation of filaggrin. Clinical manifestations of ichthyosis vulgaris are hyperlinear palmar and plantar, keratosis pilaris, xerosis, and localized or generalized scaling of the skin. Application of emollients, humectants and keratolytic agents are the main treatment of ichthyosis vulgaris. Further research on caspase-14 as a therapeutic target is needed in the treatment of ichthyosis vulgaris.
\end{abstract}

All authors have reviewed and approved the final version of the manuscript.

https://doi.org/10.32539/bsm.v5i2.214

\section{Introduction}

Skin is the largest organ in the body that has many functions and plays a role in maintaining homeostasis. As the outermost part of the body, function of skin is to protect against the penetration of chemicals and bacterial invasion. In addition, skin also has functions of absorption, excretion, perception, thermoregulation and produced vitamin D. $(1,2)$ Skin has three layers, namely the epidermis, dermis, and hypodermis. Epidermis layer is the outermost layer composed of several types of cells. The main function of epidermal layer is to protect against external environment, prevent, and resist infection through activation of immune system. Cells undergo a process of proliferation and differentiation which is then divided into four differentiations, basal layer, spinosum layer, granulosum layer, and corneum layer. $(3,4)$
Epidermal layer tightly connected to dermis through basement membrane zone (BMZ). This zone consists of four components from ultrastructural perspective: hemidesmosome, an electron lucent zone called lamina lucida, lamina densa, and sublamina densa, including anchoring fibrils, dermal microfibrils, and collagen fibers.(5) Process of keratinocyte proliferation in the epidermis starts from basal layer. Epidermal stem cells bind to hemidesmosomes in the basal layer and divided into stem cells that maintain the regeneration ability of keratinocytes, or become cells that differentiate into the stratum corneum layer through a maturation process called keratinization. After complete differentiation occurs, corneocytes lost their nucleus and cytoplasmic organelles and released through the desquamation process. Duration of keratinocyte proliferation process and epidermal differentiation from epidermal stem cells 
to desquamation in normal skin is 311 hours.(6) In the process of epidermis differentation in the granulosum layer, it has special characteristics, called keratohialin granules. Keratohyalin granules consisting of keratin, profilaggrin and loricrine are involved in the formation of cornified cell envelope (CCE). Profilaggrin is quickly converted into filaggrin which will bind to keratin. Filaggrin is broken down to form natural moisturizing factor (NMF), a pool of amino acids and derivatives to protect against ultraviolet rays. $(7,8)$

Process of epidermal proliferation and differentiation is associated with several disorders, including ichthyosis, palmoplantar keratoderma, keratosis pilaris, and epidermolysis bullosa simplex. Ichthyosis vulgaris is the most common disorder of cornification. This disorder is a genetic disorder, autosomal semi-dominant inheritance. Genetic disorder is related to the mutation of the filaggrin gene (FLG) located on chromosome 1q21 which plays an important role in the differentiation process of epidermis. Clinical manifestations of ichthyosis vulgaris are palmar and plantar hyperlinear, keratosis pilaris, xerosis, and localized and generalized scales of the skin.(9-12) This literature review will discuss the anatomical structure, histology, and physiology of epidermis, cell cycle, process of epidermal proliferation and differentiation in normal conditions and ichthyosis vulgaris, to understanding the processes.

\section{Anatomic, Histological, and Physiological Epidermal Structures}

Anatomical structure of skin epidermis in all areas of the body is generally similar and composed of the same collection of cells. Three types of cells in adult skin are keratinocytes, melanocytes, and Langerhans cells. In certain areas of the body, such as the palms of hands and soles of feet, the area of genital and oral mucosa, nail bed and the follicular infundibulum can be found the fourth cell type, namely Merkel cells.(2) Anatomical structure of the epidermis can be seen in Figure 1.

Major population of epidermal layer is keratinocytes. Keratinocytes originate from the ectoderm and produce keratin, a complex filamentous protein that forms the outer layer of the skin and a structural protein in nails and hair. Keratinocytes produced by epidermal stem cells located in the basal layer, undergo maturation, and migrate to superficial formed stratum corneum. Process of keratinocytes proliferation and maturation is 311 hours until reach the stratum corneum. $(2,6)$ During this time period, keratinocytes undergo fundamental changes in genes, expression patterns, morphology, and metabolism called keratinization. Once cells reach a state of terminal differentiation, keratinocytes will only serve as a physical barrier. In certain conditions, such as injury or inflammation, the proliferation process can occur more rapidly. $(2,13)$

Keratin intermediate filament (KIF) proteins are epithelial cells cytoskeletal component that provides mechanical stability and protection from damage. Keratin proteins take part in the formation of the KIF in epithelial cells and exist as polymeric filaments by pairing oftype I (K1-K8, K71-K86) a smaller size (40$56.5 \mathrm{kDa})$ and type II (K9-K28, K31-K40) keratin proteins a larger size $(50-79 \mathrm{kDa}) .(13,14)$

As a physical barrier, keratinocytes respond to pathogens and wounds by producing antimicrobial peptides (AMP) to kill microbes, as well as various types of cytokines that enhance and regulate immune responses. The AMP that keratinocytes produce include human $\beta$ defensins (HBD) 1,2,3, psoriasin (S100), and cathelicidin (LL 37). The cytokines made by keratinocytes include tumor necrosis factor (TNF), tymic stromal lymphopoietin (TSLP), interleukin (IL)-1, IL-6, IL-18, IL-25 and IL-33.(15)

Other cells in epidermis are melanocytes, which produce melanin through the process of melanogenesis. Melanocytes play an important role in protection function against UV radiation through melanin pigment. Melanocytes are dendritic cells that reach a number of keratinocytes. One melanocyte can reach several keratinocyte cells and form epidermalmelanin units. Melanocytes produce melanosomes, containing melanin, which are transferred to the nearest keratinocytes by excretion and phagocytosis. In 
normal circumstances, ratio of melanocytes with keratinocytes in the basal layer are 1:10, but in areas exposed to sunlight, the ratio can be 1: 1. However, differences in skin color are not influenced by the number of melanocytes in the skin, but by number, size and distribution of melanosomes in keratinocytes. Fitzpatrick skin types 5-6 have a greater number of melanosomes, tend to be larger and single scattered. Chronic sun exposure can stimulate melanocytes to produce larger melanosomes, as in people with dark skin. $(2,5)$

Langerhans cells are macrophages that originate from bone marrow. Langerhans cells scattered among keratinocytes especially in spinosum layer. Langerhans cells function to recognize, bind, process and represent antigens. Furthermore, Langerhans cells migrate out of the skin to regional lymph nodes and represent these antigens on $\mathrm{T}$ lymphocytes. Langerhans cells play an important role in immunity, especially humoral immunity. Merkel cells are located above basement membrane as sensory mechanoreceptors, especially slow-adapting touch receptors. Merkel cells contain intracytoplasmic neuroendocrine peptide granules. $(2,16)$

Connecting zone between epidermis and dermis layer, called basement membrane zone (BMZ). Ultrastructural features of the zone consist of four components, consisting of hemidesmosome, electron lucent zone called lamina lucida, lamina densa (lamina basal), and sublamina densa, consisting of anchoring fibrils, dermal microfibrils and collagen fibers. Keratin intermediate flaments attach to electron-dense hemidesmosomes on basal plasma membranes of keratinocytes. Hemidesmosomes connect to the underlying lamina densa (basement membrane proper) by small thread-like strands termed anchoring flaments.(5)

Desmosomes are multi-protein complexes that function as cell-cell adhesion structures (junctions) in epidermal cells, also provide attachment sites for the KIF cytoskeleton of keratinocytes. Desmosomes is formed mainly by transmembrane glycoproteins desmoglein (Dsg) and desmocolin (Dsc), a family of cadherins. Transmembrane proteins are linked to keratin intermediate filament network via a complex of several proteins, including desmoplakin, plakoglobin, one of several plakophilin (Pkp) isoforms. Several desmosomal components are encoded by multigen families, there are four Dsg isoforms, three Dsc isoforms, and three $\mathrm{Pkp}$ isoforms. The specific composition of the desmosome influence the adhesion properties.(18)

\section{Cell Cycle}

Coordinating cell growth and differentiation is essential to morphogenesis and adult tissue homeostasis. Skin has renewal ability, especially after being exposed to pathogens. In epidermis, proliferation occurs in the basal layer, whereas cell differentiation occurs along the migration of cells starting from the suprabasal layer. $(19,20)$

There are two conditions that occur during epidermal cell proliferation process towards differentiation process. First condition is when two daughter cells from the basal layer enter the clonal expansion phase of rapid proliferation called transit amplifying cells (TAC). The second condition is when these cells undergo terminal proliferation and differentiation. Studies have found that cells undergoing a rapid proliferation phase will differentiate after passing through four to five cell divisions by mechanisms that are not fully understood. $(19,20)$

Normal cell growth and cell mass are influenced by several internal factors, including signals which regulate proliferation, differentiation, and cell death. These factors are in part triggered by blood supply and the external environment, including soluble molecules as well as matrix-cell and cell-cell contacts. Proliferation involves DNA replication and mitosis via a series of events termed the cell cycle.(19)

In normal condition, cells dividing starts with the first gap $\left(\mathrm{G}_{1}\right)$ which occurs for 8-30 hours. This phase connects the resting phase $\left(\mathrm{G}_{0}\right)$ enters the DNA synthesis phase (S) after getting an adequate stimulus. Certain cells that exit the cell cycle and enter Go phase are destined for terminal diferentiation or senescence, 
irreversibly locked out of the cell cycle. After the S phase which occurs for approximately 8 hours, reorganization of the chromatin occurs in a second gap $\left(\mathrm{G}_{2}\right)$ followed by the mitotic phase (M).(19) The phases of the cell cycle can be seen in Figure 2.

In the cell cycle, there are 3 checkpoints in G1, G2 and $M$ phases which play a role in ensuring that cell division occurs correctly. Transition phase regulation in $\mathrm{G}_{1}, \mathrm{G}_{2}$ and $\mathrm{M}$ involves 3 main proteins: cyclin, cyclindependent kinase (CDK), and cyclin-dependent kinase inhibitor (CKI). Balance of cyclin and CKI concentrations regulates $\mathrm{CDK}$ activity. Cyclindependent kinase influenced by mitogenic growth factor as an activator, and proteolysis as an inhibitor. Cyclin-dependent kinase regulates proliferation of proteins that play a role in the cell cycle. $G_{1}$ phase influenced by the interaction of various macromolecular complexes including hormones and various growth factors such as insulin-like growth factor-1, epidermal growth factor, and platelet-derived growth factor. $(19,22)$

Cell proliferation is blocked when $\mathrm{G}_{1}$ checkpoint is underphosphorylated and cell is arrested in G1. epression can be reversed by CDK-cyclin complexmediated phosphorylation. This phosphorylation/dephosphorylation cycle can thus reversibly regulate cell cycle progression and rate of proliferation.(19)

\section{Epidermal Proliferation and Differentiation}

Proliferation is process of multiplying cells into cells with the same shape. Process of keratinocyte proliferation in the epidermis starts from the stratum basale. Keratinocyte stem cells are bound to hemidesmosomes in the stratum basale and divide into stem cells that maintain the regeneration ability of keratinocytes, or become cells that continue to differentiate into the stratum corneum.(6) There are two models of keratinocyte stem cell division, hierarchical and stochastic. In the hierarchical model, stem cells undergo asymmetric division into one new stem cell and one TAC. Transit amplifying cells will divide rapidly and symmetrically to produce two TACs then start terminal differentiation. In the stochastic model, epidermal stem cell division are rare and usually asymmetrical, producing a new stem cell and a progenitor or two stem cells or two progenitor cells. Progenitor cells make up the bulk of the basal layer, divide frequently into new progenitor cells and cells that leaves the basal layer to undergo terminal differentiation.(23) The division processes of the two keratinocyte stem cell models can be seen in Figure 3.

Differentiation is the process of multiplying cells from one cell into many, with homogeneous to heterogeneous characteristics. Epidermis consists of four differentiations arranged sequentially from deep to superficial. On the palms of the hands and soles of the feet there is a thin, flattened layer of eosinophilic cells called the lucidum layer, which located between the corneum layer and granulosum layer. However, in some literature, this layer is often not mentioned specifically. The four epidermal differentiations are:

1) Basal layer is deepest layer of the epidermis and generally consists of a layer of cuboid cells. The constituent cells are epidermal stem cells, and TAC. Keratinocyte cells made up this layer. Melanocyte are present in the basal layer and make up 5-10\% of the cell population.

2) Spinosum layer is also known as the malphigian layer, consisting of cuboidal cells with protrusions that are attached to each other with desmosomes. In this layer, various lipids and proteins are synthesized and modified which play a role in barrier function and hydration of the layer above. Within this layer Langerhans cells can be identified.

3) Granulosum layer consist of 3-5 layers of flat polygonal cells with a cytoplasm consisting of keratohyalin granules. Keratohyalin granules contain keratin, prophylagrin, loricrine, and other proteins that form a cornified cell envelope (CCE). Keratin, loricrine and other proteins are crosslinked by transglutaminases to the plasma membrane. Keratohialin granules which contain prophylagrin will undergo dephosphorylation and proteolysis to form filaggrin and will be metabolized into pyrrolidone carboxylic acid, and urocanic acid 
as a natural moisturizing factor (NMF) which functions as a hydration and ultraviolet (UV) protector. The process of profilaggrin breakdown can be seen in Figure 4. $(2,7,24,25)$

4) Corneum layer consists of 15-20 layers of squamous cells without a nucleus. The keratinocyte cytoplasm of the keratinocyte cells in this layer is filled with keratin which is bound to filaggrin. The corneum layer barrier consists of keratinocyte components bound by $\mathrm{CCE}$ and encased in intercellular lipid lamellae, consisting of cholesterol, free fatty acids, and ceramide. These components play an important role in maintaining transepidermal water. In this layer, intercellular compartments connected by corneo-desmosomes which undergo proteolytic degeneration. Process of epidermal proliferation and differentiation which consists of four differentiations can be described in Figure 5.

\section{The Regulation of Epidermal Differentiation}

Process of epidermal differentiation is the transformation of cells that proliferate in the basal layer into corneum layer. Mitotically active keratinocytes in the basal compartment of epidermis primarily expres the keratin pair K5 and K14, with less abundant expression of K15. Keratinocytes migrate from the suprabasal to the stratum spinosum and downregulation of $\mathrm{K} 5$ and $\mathrm{K} 14$ proteins and induction of the differentiation-spesific keratin K1 and K10. Further maturation process of spinous keratinocytes into granular keratinocytes, result in expression of $\mathrm{K} 2$. Number of epidermal keratins have a more restricted anatomic distribution pattern. For example, K9 is specifically expressed in the suprabasal cells of palmoplantar epidermis. K6, K16 and $\mathrm{K} 17$ are expressed not only in the palmoplantar epidermis, but also in keratinocyes of the nail bed, hair follicle, sweat and sebaceous glands. $(18,20)$

Several pathways play an important role in the differentiation of normal keratinocytes. These pathways mainly play role in building and maintaining basal keratinocytes, initiating and executing terminal differentiation and forming the corneum layer. Each pathway influenced by certain genes. In the initiation phase, the TP63 gene plays an important role in maintaining morphogenesis and regulating various transcription factors in basal keratinocytes. The p63 protein induces $\mathrm{K} 5$ and $\mathrm{K} 14$ expression and represses K18 expression. p63 protein also maintain cell proliferation phase in basal keratinocytes by repressing genes that express cell cycle inhibitor proteins.

In addition, p63 protein, especially the $\Delta \mathrm{Np} 63 \mathrm{a}$ isoform, plays a role in the terminal differentiation of keratinocytes. p63 protein in conjunction with the signal notch pathway (a signal that plays a role in regulating epidermal proliferation and differentiation) induces K1 expression. Simultaneously, p63 protein also mediates the excretion of differentiated keratin from the cell cycle. Another factor that plays an important role in the differentiation process of keratinocytes is the concentration of calcium. There is an increasing gradient of extracellular calcium concentration found in the basal layer to the corneum layer. In the granulosum layer there are various proteins that are influenced by the concentration of calcium, for example protein kinase C (PKC) plays a role in the transition of cells from spinous cells to granular cells.(18)

\section{Epigenetics in The Regulation of Epidermal Differentiation}

Epigenetics refers to phenotypic changes caused by mechanisms other than DNA damage. Epigenetics mechanisms play an important role in growth and differentation of keratinocytes by regulating the expression of genes in $2 \mathrm{Mb}$ region of human chromosome 1q21. This area regulates epidermal differentiation complex (EDC). These genes regulate various structural proteins, including regulating $\mathrm{CCE}$ and various proteins bound to calcium. Epigenetics is involved in several mechanisms related to epidermal differentiation. Several mechanisms of epigenetic involvement in cell differentiation are related to ATPdependent and chromatin remodeling. Another mechanism that occurs can be through DNA methylation and covalent histone modification.(4) 
Epigenetic effects on chromatin remodeling involved Brahma (BRM) or Brahma-related gene 1 (BRG1) ATPase, have partially overlapping functions in keratinocyte terminal differentiation. Both genes are not involved in the early stage of the process but severely impair the final stage of terminal differentiation leading to skin barrier defects. Further, under this p63-regulated BRG1-dependent chromatin remodelling programme, another genome organizer, Special AT-Rich Sequence-Binding Protein 1 (SATB1) is also activated to induce transcription of gene required for the terminal differentiation of keratinocytes.(4)

Epigenetic involvement through histone modification can be found in the Histone Deacetylase (HDAC) - 1 and 2 genes which play a role in repression of p63 and p53 function, and indirectly affect SATB1. A recent study also found that deficiency of the aryl hydrocarbon receptor nuclear translocator (ARNT) causes down-regulation of the amphiregulin / epidermal growth factor receptor pathway by activation of HDAC1, HDAC2, and HDAC3. This signaling pathway is related to the balance of keratinocyte proliferation and differentiation.(4)

Study also found that elevated Zeste homologs $(\mathrm{EZH}) 1$ and 2 were associated with the regulation of genes regulating filaggrin, involucrine and loricrine. All three are genes found in areas that regulate keratinocyte differentiation. These findings support the role of epigenetics in the differentiation process of keratinocytes. Epigenetic involvement through the methylation or hypermetilation process of DNA is mainly found in the involvement of DNA methyltransferase 1 (DNMT-1). In the case of psoriasis, hypermetilation occurs in the area of genes related to immune regulation, cell cycle and apoptosis.(4)

\section{Ichthyosis Vulagaris}

Ichthyosis vulgaris, also known as ichthyosis simplex, is the most common keratinization disorder. This disorder is found in 1 in 100 to 250 people. This disturbance is influenced by seasons, especially in winter and dry. Understanding proliferation and differentiation processes of normal keratinocytes as described can help understand the pathogenesis of ichthyosis vulgaris.

\section{Pathogenesis of Ichthyosis Vulgaris}

Ichthyosis vulgaris is a genetic disorder semidominant autosomal inheritance. In ichthyosis vulgaris, there is no abnormality of the epidermal proliferation process. Disorder of ichthyosis vulgaris begins in the differentiation process in the granular layer. This genetic disorder is related to the filaggrin gene (FLG) located on chromosome 1q21 which plays an important role in epidermal differentiation. $(9,27,28)$ (Figure 6)

Filaggrin is a component of keratohyalin granules found in the granular layer. Filaggrin is the result of the breakdown of profilaggrin protein which functions as KIF aggregation. These bonding complexes are crosslinked and are responsible forming the cell envelope. Filaggrin degraded into amino acids, especially histidine. This amino acid can retain water so that it functions as NMF. In addition, these amino acids can function as a skin barrier against allergens and pathogens. $(9,27)$ The KIF bond complex with the filaggrin can be seen in Figure 7. Filaggrin deficiency causes cornification disorders and increased transepidermal water loss. In addition, filaggrin deficiency also leads increased penetration of allergens, irritants and an inflammatory response. In addition, an association between FLG mutations and elevated serum vitamin D (25-OH D) levels may result from increased UVB-induced vitamin D production in the skin, perhaps related to a paucity of urocanic acid, a photoprotective histidine metabolite. Several studies stated that patients with ichthyosis vulgaris increase in serum vitamin D levels occurred only $10 \%$ and not in all types of ichthyosis vulgaris. Patient with ichtiosis vulgaris avoid the warm of the sun because it increases cutaneous pain and pruritus.(9)

Sebaceous glands cannot regenerate but are replaced by differentiation of epidermal cells to compensate for the damaged barrier. In the corneum layer the $\beta$-glucocerebrosidase (GCerase) and acid sphingomyelinase (SMase), metabolize 
glycosylceramides (Gcer) and Sphyngomyelin (SM) to ceramide. Both enzimes require an acidic environment of $\mathrm{pH}<5.5$ for their optimal activity. Lack of FLG could resulit in an increased skin $\mathrm{pH}$, bacteria colonization and decreased production of ceramide. $(29,30)$

The genetic abnormalities that underlie this patient's disease affect the clinical manifestations that occur. Patients with heterogeneous mutations in the filaggrin constituent genes will manifest as mild abnormalities, however, in patients with filaggrin deficiency due to mutations in both alleles, it will manifest as severe abnormalities. Heterozygous mutation disorders are found in $80-95 \%$ of cases of ichthyosis and related disorders such as hyperlinear palms, keratosis pilaris or atopic dermatitis. Typical clinical manifestations of ichthyosis vulgaris are localized and generalized ichthyosiform scale of the skin. $(9,27,28)$

The mutations that are often found in European populations are R501X and 22282del4, while in Asian populations are more diverse mutations. A new study conducted in 2004 by Kirchmeier et al found that ichthyosis can occur in a double-allele mutation of the CASP14 gene which is responsible for the production of cysteinyl aspartate - specific proteinase (caspase) -14. The CASP14 gene is located on chromosome 19p13.12 and is inherited in an autosomal recessive manner. Deficiency of caspase-14 affects the proteolytic degradation of filaggrin. Patients with the CASP14 mutation cause the difference in manifestation between ichthyosis vulgaris and the mild form of autosomal recessive congenital ichthyosis (ARCI) to be unclear. $(11,27)$

The main treatment for ichthyosis vulgaris is the use of emollients, humectants and keratolytic agents to reduce squama. Preparations containing urea, lactic acid, glycolic acid or salicylic acid are very useful.(28) Retinoids are compounds that activate retinoid receptors. Retinoid receptors bind to transcription factors. The retinoid receptors found in humans are retinoid acid receptors (RAR) and retinoid $X$ receptors (RXR) with $a, \beta, \gamma$ subtypes. When RAR and RXR bind to retinoid-acid responsive elements (RARE) it stimulates transcription genes in basal cells. Metabolism of retinoids will produce changes in transcription genes that will increase the process of proliferation, differentiation and apoptosis. $(31,32)$ Denecker et al showed whether caspase-14, its activating protease, or its substrates could be used as therapeutic agents or as targets to improve formation of the epidermal barrier is a challenging research goal.(33) The use of retinoids as a therapy of ichtyosis vulgaris is not recommended because it will increase skin irritation and reduce levels of caspase 14 which regulates the breakdown of filaggrin as NMF. The defects that arise in ichthyosis vulgaris are found in the granular layer, while the retinoid mechanism process will affect the transcription genes from the basal layer.(33) 


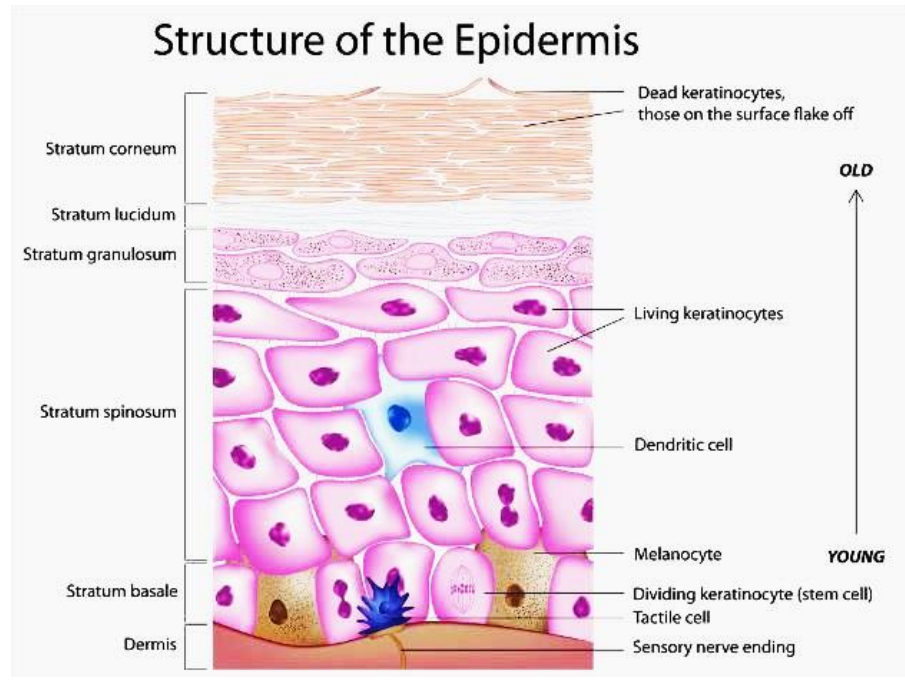

Figure 1. Epidermal anatomy.(17)

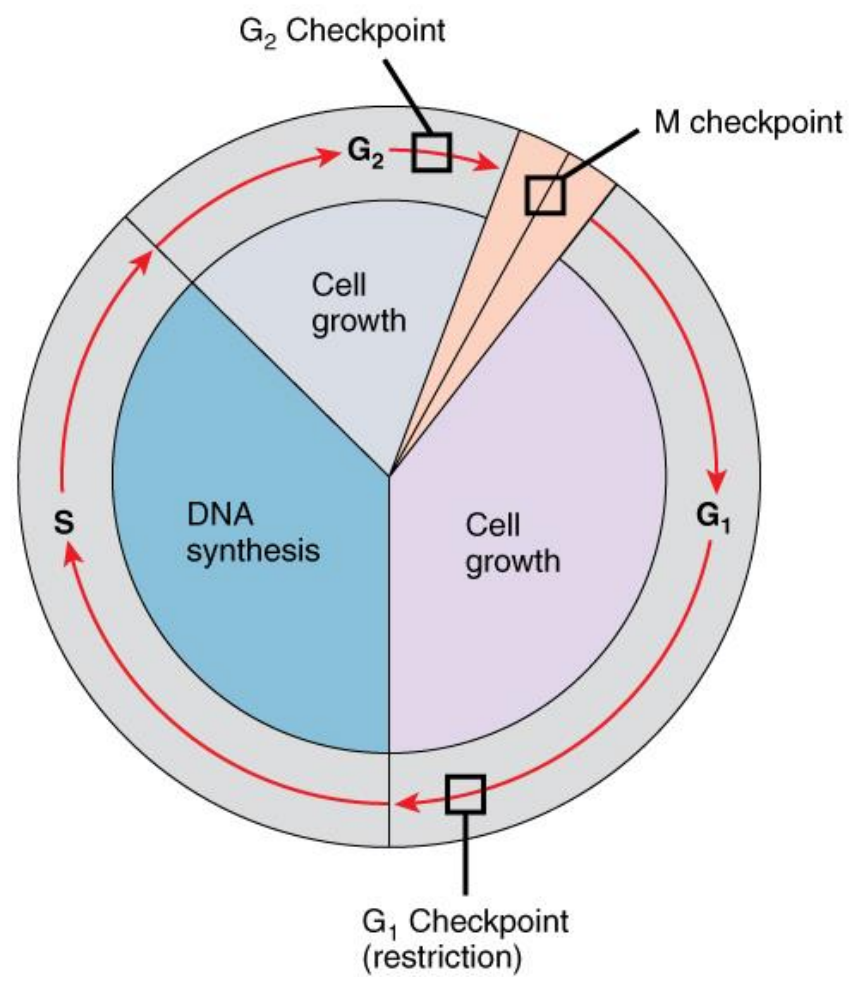

Figure 2. Cell Cycle: Two phase gap $\left(\mathrm{G}_{1}\right.$ and $\left.\mathrm{G}_{2}\right)$; phase $\mathrm{S}$ (synthesis), duplication of genetic material; and phase $\mathrm{M}$, the mitotic division of genetic material and cells. (21) 


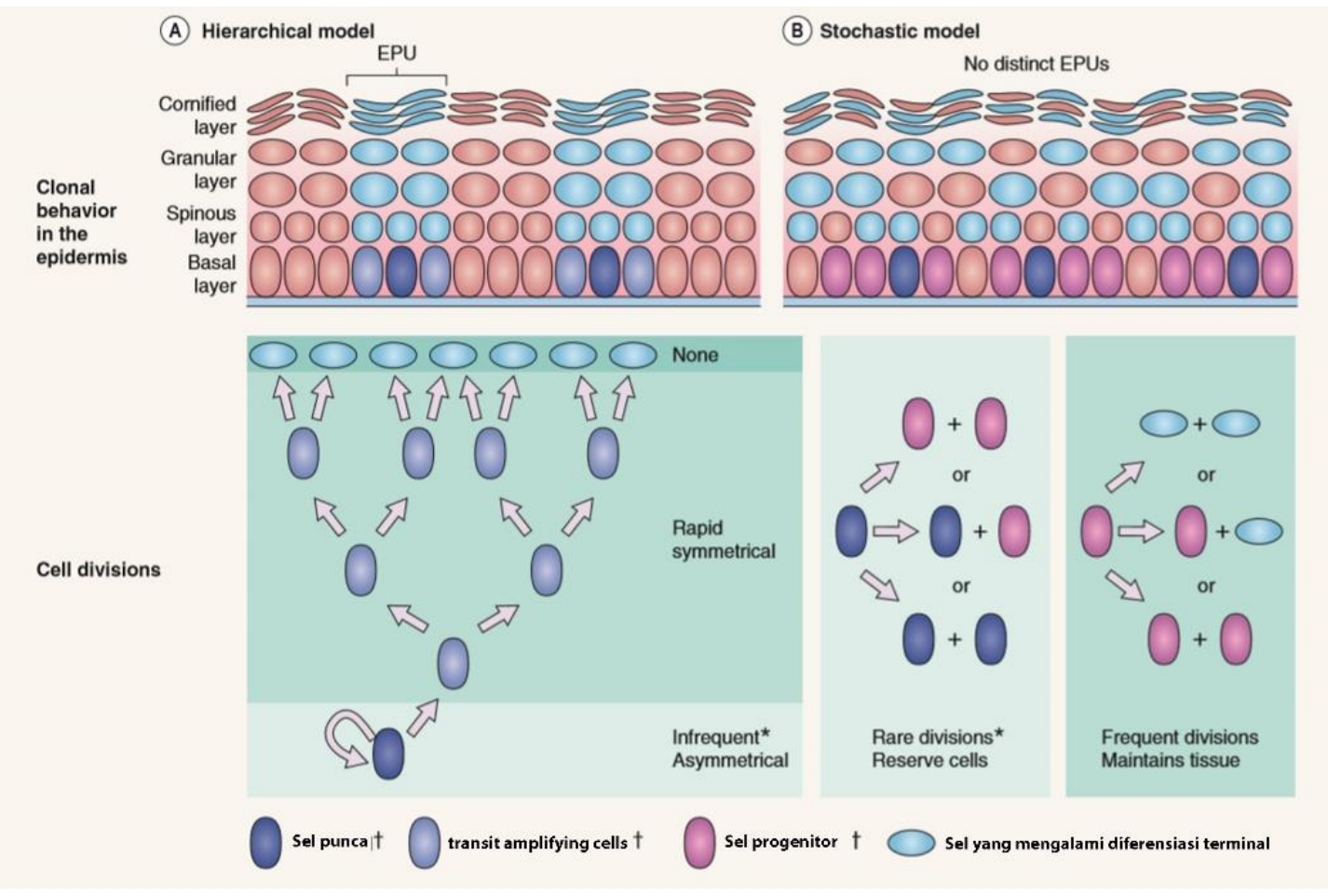

Figure 3. Model of keratinocyte stem cell division.(23)

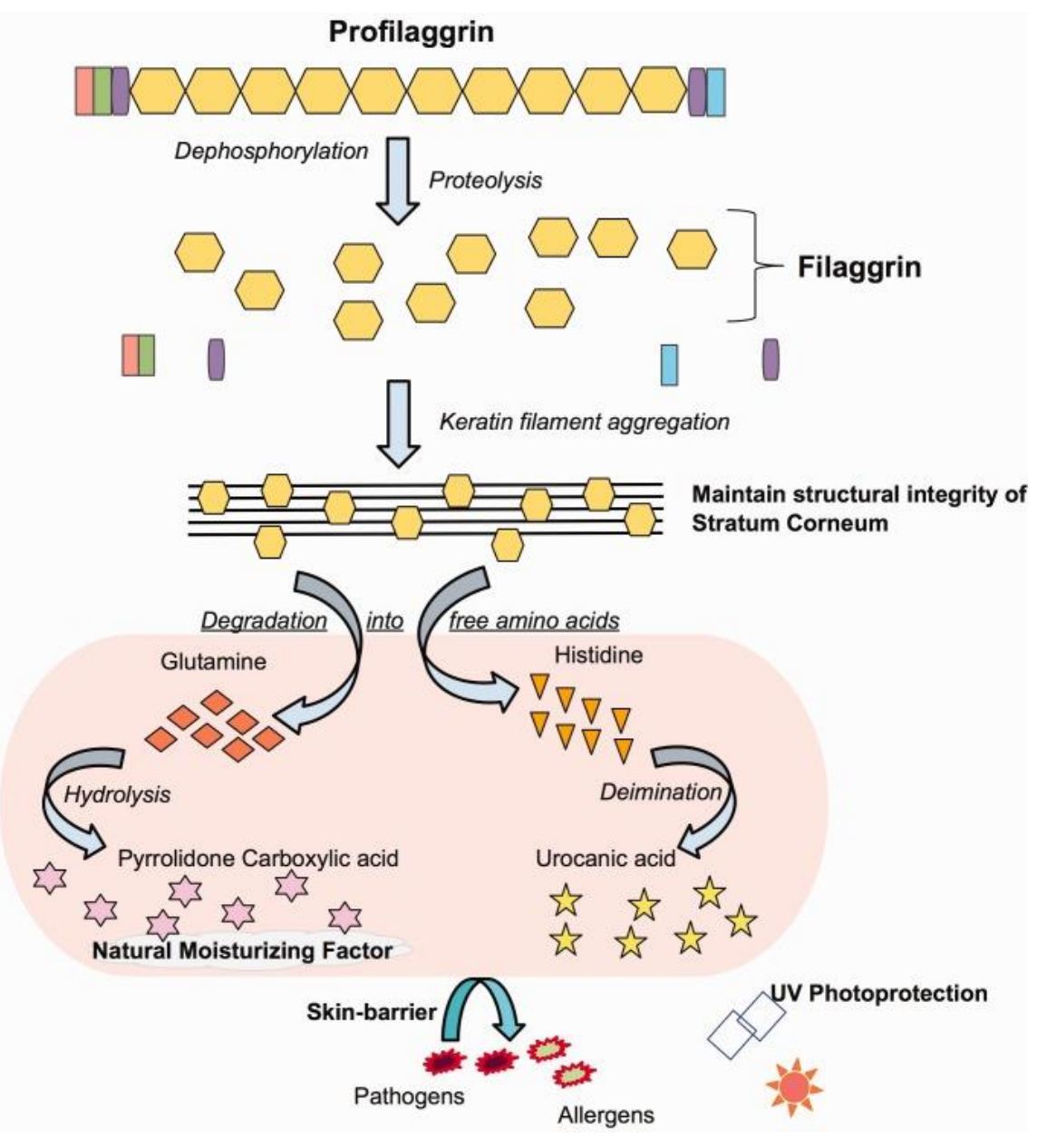

Figure 4. The roles of structural units of the FLG(26) 


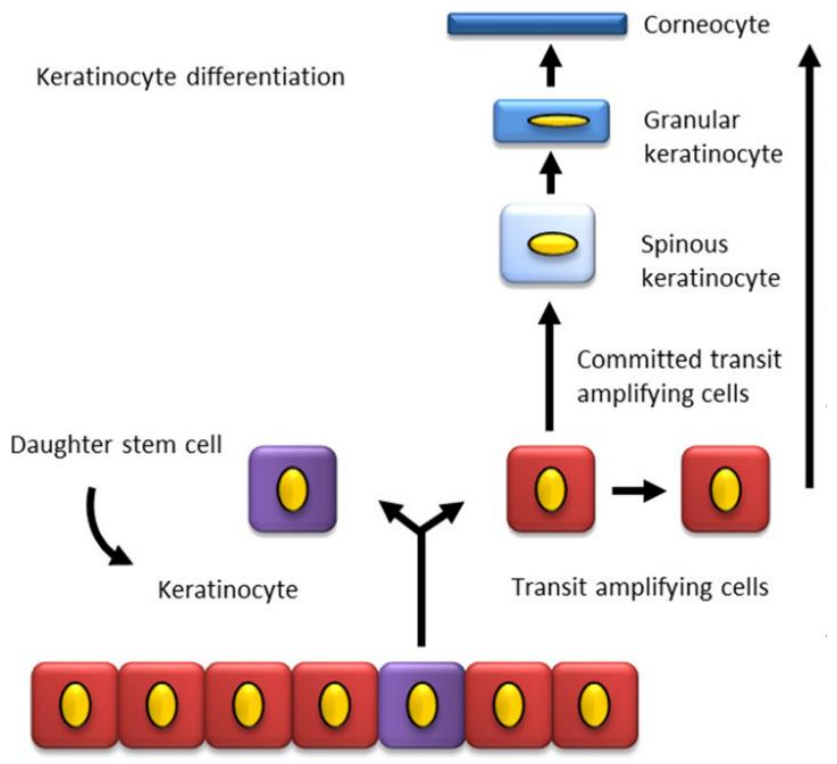

Figure 5. Schematic overview of epidermal differentiation(6)

\section{Gen FLG}

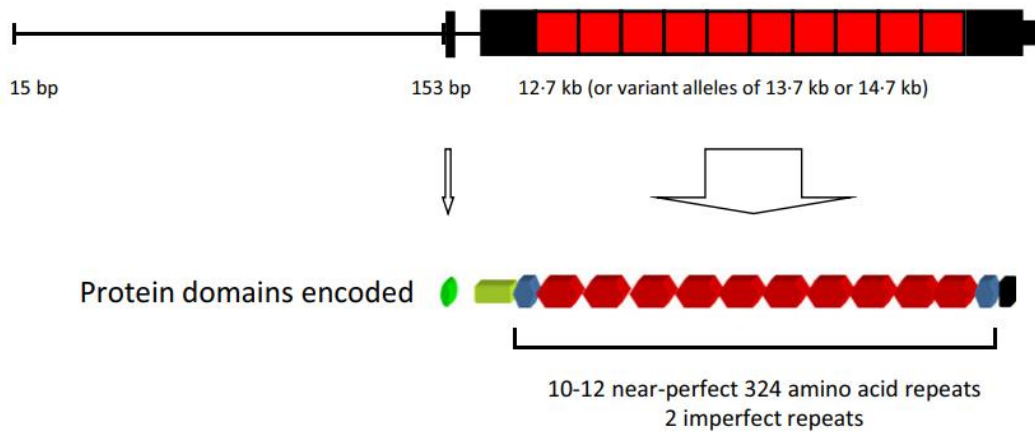

Figure 6. Schematic Image of Filaggrin(8)

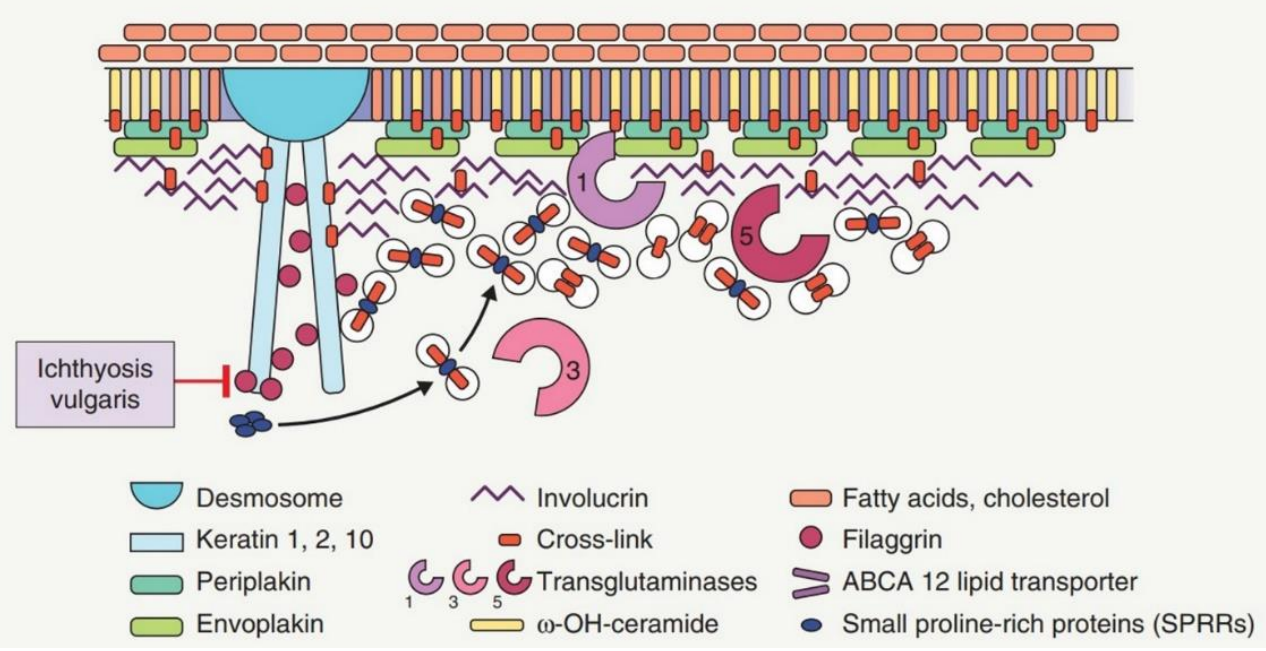

Figure 7. Keratin and filaggrin complexes in ichthyosis vulgaris.(18) 


\section{Conclusion}

Normal epidermal proliferation and differentiation occurs physiologically starting from stem cells found in the basal layer. Keratinocytes have the ability to regenerate through stem cell division in the cell cycle which will differentiate to the corneum layer through the maturation process. In the granular layer there are keratohialin granules consisting of prophylagrin and loricrine which are important in the formation of CCE. Disorders of the filaggrin gene (FLG) on chromosome 1q21 and recent research on the double-allele mutation of the CASP14 gene on chromosome 19p13.12 cause ichthyosis vulgaris. Further research is needed on the use of caspase-14 as a therapeutic target in the treatment of ichthyosis vulgaris.

\section{Acknowledgements}

The authors report no financial support and no conflicts of interest.

\section{References}

1. High WA, Tomasini CF, Argenziano G, Zalaudek I. Basic principles of dermatology. In: Bolognia JL, Schaffer JR, Cerroni L, editors. Dermatology. 4th ed. New York: Elsevier; 2018. p. $1-43$.

2. Vandergriff TW. Anatomy and physiology. In: Bolognia JL, Schaffer JR, Cerroni L, editors. Dermatology. 4th ed. New York: Elsevier; 2018. p. 44-55.

3. Garza L. Developmental Biology of The Skin. In: Kang S, Amagai M, Bruckner AL, Enk AH, Margolis DJ, McMichael AJ, et al., editors. Fitzpatrick's Dermatology. 9th ed. New York: McGraw Hill; 2019. p. 49-61.

4. Abhishek S, Krishnan SP. Epidermal differentiation complex: A review on its epigenetic regulation and potential drug targets. Cell J. 2016;18(1):1-6.

5. James WD, Elston DM, Treat JR, Rosenbach MA, Neuhaus IM. Skin: Basic structure and function. In: Andrews' Diseases of the Skin. $13^{\text {th }}$ ed. New York: Elsevier; 2020. p. 1-10.

6. Horst B terr, Chouhan G, Moiemen NS, Grover LM. Advances in keratinocyte delivery in burn wound care. Adv Drug Deliv Rev. 2018;123:1832 .

7. Lechler T. Growth and differentiation of the epidermis. In: Kang S, Amagai M, Bruckner AL, Enk AH, Margolis DJ, McMichael AJ OJ, editor. Fitzpatrick's Dermatology. 9th ed. New York: McGraw Hill; 2019. p. 62-9.

8. McLean WHI. Filaggrin failure - from ichthyosis vulgaris to atopic eczema and beyond. $\mathrm{Br} \mathrm{J}$ Dermatol. 2016;175:4-7.

9. Richard G, Ringpfeil F. Ichthyoses, erythrokeratodermas, and related disorders. In: Bolognia JL, Schaffer $\mathrm{J} \mathrm{V}$, Cerroni L, editors. Dermatology. 4th ed. New York: Elsevier; 2018. p. 888-923.

10. Marukian N V, Choate KA. Recent advances in understanding ichthyosis pathogenesis. F1000 Fac Rev. 2016;5(0):1-9.

11. Kirchmeier P, Zimmer A, Bouadjar B, Rösler B, Fischer J. Whole-exome-sequencing reveals small deletions in CASP14 in patients with autosomal recessive inherited ichthyosis. Acta Derm Venereol. 2017;97(1):102-4.

12. Wang $\mathrm{X}$, Tan $\mathrm{L}$, Shen $\mathrm{N}$, Lu Y, Zhang $\mathrm{Y}$. Exacerbation of ichthyosis vulgaris phenotype by co-inheritance of STS and FLG mutations in a Chinese family with ichthyosis: A case report. BMC Med Genet. 2018;19(1):1-5.

13. Min M, Chen XB, Wang P, Landeck L, Chen JQ, Li W, et al. Role of keratin 24 in human epidermal keratinocytes. PLoS One. 2017;12(3):1-16.

14. Jacob JT, Coulombe PA, Kwan R, Omary MB. Types I and II keratin intermediate filaments. CSH PERSPECT BIOL. 2018;10(4):1-10.

15. Abbas AK, Lichtaman AH, Pillai S. Specialized immunity at epithelial barriers and in immune privileged tissues. In: Cellular and Molecular Immunology. 9th ed. New York: Elsevier; 2018. 
p. 299-324.

16. Kolarsick PAJ, Kolarsick M, Goodwin C. Anatomy and Physiology of the Skin. J Dermatol Nurses Assoc. 2011;3(4):203-13.

17. Alsaab HO. Thesis: Evaluation of the Percutaneous Absorption of Chlorpromazine Hydrochloride from PLO Gels Across Porcine Ear and Human Abdominal Skin (PDF Download Available). Univ Toledo [Internet]. 2016; Available from: https://www.researchgate.net/publication/30 8886028_Thesis_Evaluation_of_the_Percutane ous_Absorption_of_Chlorpromazine_Hydrochlo ride_from_PLO_Gels_Across_Porcine_Ear_and_ Human_Abdominal_Skin

18. Arin MJ, Roop DR, Koch PJ, Koster MI. Biology of keratinocytes. In: Bologinia JL, Schaffer J V, Cerroni L, editors. Dermatology. 4th ed. New York: Elsevier; 2018. p. 876-87.

19. Colegio OR, O’Toole EA, Pontén F, Lundeberg $\mathrm{J}$, Asplund A. Principles of tumor biology and pathogenesis of BCCs and SCCs. In: Bolognia JL, Schaffer J V, Cerroni L, editors. Dermatology. 4th ed. New York: Elsevier; 2018. p. $1858-71$.

20. Zanet J, Freije A, Ruiz M, Coulon V, Sanz JR, Chiesa J, et al. A mitosis block links active cell cycle with human epidermal differentiation and results in endoreplication. PLoS One. 2010;5(12).

21. The Cell Cycle, Mitosis and Meiosis [Internet]. University of Leichester. [cited 2020 Jul 27]. Available from: https://www2.le.ac.uk/projects/vgec/highere ducation/topics/cellcycle-mitosis-meiosis

22. Gross SM, Rotwein P. Unraveling growth factor signaling and cell cycle progression in individual fibroblasts. $\mathrm{J}$ Biol. 2016;291(28):14628-38.

23. Brownell I, Loomis CA, Koass T. Skin Development and Maintenance. In: Bolognia JL, Schaffer J V, Cerroni L, editors. Dermatology. 4th ed. Ney York: Elsevier; 2018. p. 56-65.

24. Venus M, Waterman J, McNab I. Basic physiology of the skin. Surgery. $2011 ; 29(10): 471-4$.

25. Sandilands A, Sutherland C, Irvine AD, McLean WHI. Filaggrin in the frontline: Role in skin barrier function and disease. J Cell Sci. 2009;122(9):1285-94.

26. Eaaswarkhanth $\mathrm{M}, \mathrm{Xu} \mathrm{D}$, Flanagan $\mathrm{C}$, Rzhetskaya M, Hayes MG, Blekhman R, et al. Atopic dermatitis susceptibility variants infilaggrin hitchhike hornerin selective sweep. Genome Biol Evol. 2016;8(10):3240-55.

27. Vahlquist A, Fischer J, Törmä H. Inherited nonsyndromic ichthyoses: an update on pathophysiology, diagnosis and treatment. Am J Clin Dermatol. 2018;19(1):51-66.

28. Choate KA, Milstone LM. The Ichthyosis. In: Kang S, Amagai M, Bruckner AL, Enk AH, Margolis DJ, McMichael AJ, et al., editors. Fitzpatrick's Dermatology. 9th ed. New York: McGraw Hill; 2019. p. 775-815.

29. Vávrová K, Henkes D, Strüver K, Sochorová M, Školová B, Witting MY, et al. Filaggrin deficiency leads to impaired lipid profile and altered acidification pathways in a 3D skin construct. $\mathrm{J}$ Invest Dermatol. 2014;134(3):746-53.

30. Gruber R, Sugarman JL, Crumrine D, Hupe M, Mauro TM, Mauldin EA, et al. Sebaceous gland, hair shaft, and epidermal barrier abnormalities in keratosis pilaris with and without filaggrin deficiency. Am J Pathol. 2015;185(4):1012-21.

31. Saurat J, Sorg O. Retinoids. In: Bolognia J, Schaffer J, Cerroni L, editors. Dermatology. 4th ed. New York: Elsevier; 2018. p. 2200-13.

32. Chien A, Vahlquist A, Saurat J, Boorhees J, Kang S. Retinoids. In: Kang S, Amagai M, Bruckner AL, Enk AH, Margolis DJ, McMichael AJ, et al., editors. Fitzpatrick's Dermatology. 9th ed. New York: McGraw Hill; 2019. p. 3395405. 
33. Denecker G, Ovaere P, Vandenabeele P, Cell Biol. 2008;180(3):451-8.

Declercq W. Caspase-14 reveals its secrets. J 